\title{
NOTE ON AN APPARATUS FOR EVAPORATING ETHEREAL SOLUTIONS.
}

Br G. P. GIRDIVOOD, M.D., F.I.C.

A GLASs tube is bent over, so as to make an inverted siphon. One end is opened out into the shape of a funnel, and the other end projects several inches below the level of the solution to be evaporated. The watch-glass containing the ethereal solution is placed directly under the funnel-shaped opening; then, by gently sucking the long arm of the tube, the ether vapour siphons over, and crystals are finally deposited in a small space in the centre of the watch-glass.

The same means may be adopted for concentrating an ethereal solution in a test-tube or beaker by lowering the funnel of the siphon as the ether evaporates.

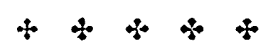

